\title{
Modelos teóricos em ciência da informação - abstração e método científico
}

\section{Luís Fernando Sayão}

Físico (UFRJ). Mestre e doutor em Ciência da Informacão (IBICT/ UFRJ). Chefe da Divisão de Tecnologia da Informacão do Centro de Informações Nucleares da Comissão Nacional de Energia Nuclear (CNEN/CIN). Consultor do IBICT/Prossiga - MCT

Sayao@cnen.gov.br

\section{Resumo}

Analisa a importância dos modelos enquanto recurso metodológico e instrumento de abstração destinado à aquisição de novos conhecimentos, representação e compreensão da realidade, especialmente no contexto das áreas cujo interesse são os fenômenos relacionados à informação, como a informática e a ciência da informação. Examina, na literatura sobre modelos e modelagem, a natureza, características básicas, funções e principais tipos de modelos. Analisa a adequação dos instrumentos de modelagem ao desenvolvimento de sistemas de informação, considerando todo o quadro perceptivo dos usuários e enfatizando a aplicação de modelos aos sistemas de recuperação de informação, principalmente aqueles que privilegiam aspectos cognitivos. Conclui que mais pesquisas sobre a representação de como as pessoas se posicionam diante da informação são extremamente necessárias para a concepção de sistemas de informação que preencham as necessidades de seus usuários.

\section{Palavras-chave}

Modelos cognitivos; Modelos semânticos; Modelagem; Desenvolvimento de sistemas de informação; Método científico; Abstração; Necessidades de informação de usuários; Recuperação da informação.

\section{Theoretical models in information science abstraction and scientific method}

\begin{abstract}
The article analyses the importance of the models while methodological resource and abstaction instrument oriented to the acquisition of new knowledge, representation and comprehension of the reality, specially within the context of subject areas whose interest are the phenomena related to information, such as Informatics and Information Science. It examines the arguments that the literature presents on models and modelling, analysing the nature of the models, their basic characeristics, functions and the main types of models. It also analyses the adequacy of the modelling instruments to the development of information systems that considers the whole perceptive view of the users, emphasizing the application of the models to information retrieval systems, mainly those that consider the cognitive aspects. It concludes that more researches on how people face information are extremely needed for the conception of information systems that will have to fulfill the users' needs.
\end{abstract}

\section{Keywords}

Modelling; Development of information systemsj; Scientific method; Abstraction; Users' information needs; Information retrieval.

\section{INTRODUÇÃO}

Na busca de novos esclarecimentos e conhecimentos, de novos fenômenos e eventos, o ser humano não os identifica somente pelas sensações ou pelas manifestações imediatas, mas recorre à reflexão e ao conhecimento acumulado, através da formulação de hipóteses e da estruturação de modelos $^{1}$. Dessa forma, a abstração constitui uma ferramenta poderosa no exercício eterno de aquisição de conhecimento, uma vez que, para se compreender a imensa variedades de formas, estruturas, comportamentos e fenômenos residentes no nosso universo, é necessário selecionar aqueles de maior relevância para o problema objeto de investigação e elaborar para eles descrições adequadas. Constroem-se, assim, esquemas abstratos da realidade, nos quais as coisas são reduzidas a seus perfis mais convenientes. "O conhecimento racional é, dessa forma, um sistema de símbolos e conceitos abstratos, caracterizado pela estrutura seqüencial e linear tão típica de nosso pensamento e de nossa fala"2.

Nesse sentido, a evolução da humanidade no seu aspecto mais abrangente - a evolução das ciências, artes, filosofia, tecnologia - pode ser encarada como um trajetória rumo à aquisição progressiva da capacidade individual de abstração. De um ser intimamente ligado à natureza, ao mundo real, concreto e objetivo, o homem tornou-se ao longo do tempo um ente independente, isolado e com cada vez maior capacidade de introspecção 3 .

Os cientistas, hoje em dia, apercebem-se do fato de que todas as suas teorias são criações da mente humana; são propriedades do nosso mapa conceitual da realidade, e não pertencentes ao domínio da realidade. Esse esquema conceitual é necessariamente limitado e aproximado como, de resto, o são todas as teorias científicas.

Segundo Capra², "o que torna a ciência tão bem-sucedida é a descoberta de que podemos utilizar aproximações. Se nos satisfizermos com uma 'compreensão' aproximada da natureza podemos descrever grupos selecionados de fenômenos, negligenciando outros que se mostrem menos relevantes. Assim podemos explicar muitos fenômenos em termos de poucos e, conseqüentemente, compreender diferentes aspectos da natureza de forma aproximada, sem 
precisar entender tudo ao mesmo tempo. Esse é o método científico: todas as teorias e modelos científicos são aproximações da verdadeira natureza das coisas; o erro envolvido na aproximação é, não raro, suficientemente pequeno para tornar significativa essa aproximação"

Dessa forma, um modelo é uma criação cultural, um "mentefato", destinada a representar uma realidade, ou alguns dos seus aspectos, a fim de torná-los descritíveis qualitativa e quantitativamente e, algumas vezes, observáveis. A existência de modelos jaz na impossibilidade cultural de descrever os objetos com perfeição, esgotando as possibilidades de sua observação. Não sendo transparente para o homem, o mundo se lhe apresenta como um permanente desafio à sua descrição. Essa limitação filosófica de percepção é que permite e exige o aparecimento de modelos ${ }^{1}$.

Dentre os vários aspectos, os modelos apresentam uma analogia, sempre que possível, mas nem sempre desejável, com o objeto real. Por analogia entende-se a representação de uma mesma função em diversos materiais e por meio de princípios diversos. Ela pode ser construída por meio de formalismos matemático, fenomenológico ou conceitual. É mais simplificada, permite testar hipóteses, tirar conclusões, caminhar no sentido da generalização e da particularização, através de processos de indução, e tem sempre uma vida provisória.

Cada modelo expressa e justifica um método de abordagem de um realidade física, ao mesmo tempo em que cada método subentende um modelo, nem que seja um modelo meramente operacional.

Os modelos apresentam também uma dimensão heurística, na medida em que, criado para explicar e fazer compreender alguns aspectos de uma realidade, são factível de evolucão e de assegurar a percepção de outros aspectos não imaginados antes de sua elaboração.

Por outro lado, uma mesma realidade física pode possuir mais de um e diferentes modelos, como acontece com o núcleo atômico. Cada modelo se destina a explicar faixas características de fenômenos nucleares, podendo, além de suas limitações, chegar a explicações complementares ou contraditórias com outros modelos.

\section{A Natureza dos Modelos}

Os modelos, em uma generalização arriscada, buscam a formalização do universo através de meios de expressões controláveis pelo ser humano; derivam da necessidade humana de entender a realidade aparentemente complexa do universo envolvente. São, portanto, representações simplificadas e inteligíveis do mundo, que permitem vislumbrar características essenciais de um domínio ou campo de estudo. A necessidade de idealização é, portanto, uma reação tradicional do homem à aparente complexidade da realidade em que está submerso. A mente tenta decompor o mundo real em uma série de sistemas simplificados e atingir assim em um único ato "uma visão das características essenciais de um domínio"4. Esta simplificação exige criatividade, tanto sensorial quanto intelectual, o que, evidentemente, implica admitir-se que, na construção de modelos, algumas características da realidade, que não se referem diretamente aos objetivos buscados, são desprezadas ou abandonadas, em função da maior inteligibilidade ou facilidade de compreensão ${ }^{5}$.

Enquanto representação de algum aspecto da realidade, um modelo assume a natureza ambígua de ser igual e desigual à realidade que ele modela. Ele possui a sua própria forma e estrutura, independentemente do original que representa; as afinidades e divergências entre o modelo e a realidade devem ser "expressáveis" e expressadas. Dessa forma, um modelo também exige um modo de expressão que pode ser, só para exemplificar alguns, gráfico, procedural, discursivo ${ }^{6}$.

Um modelo serve a muitos propósitos, mas serve fundamentalmente para comunicar alguma coisa sobre o objeto da modelagem de forma a gerar um entendimento mais completo sobre a realidade; a ação de modelar, por sua vez, impõe a quem modela uma visão clara e sem ambigüidades de quem ou do que está sendo modelado, além de exigir uma correta seleção dos elementos do universo do discurso que comporão a visão a ser representada.

Como observam Haggett \& Chorley $^{5}$, “um modelo é uma estruturação simplificada da realidade que apresenta supostamente características ou relações sob forma generalizada. Os modelos são aproximações altamente subjetivas, no sentido de não incluírem todas as observações e mensurações e medições associadas, mas, como tais, são valiosas por ocultarem detalhes secundários e permitirem o aparecimento dos aspectos fundamentais da realidade. Esta seletividade significa que os modelos têm graus variáveis de probabilidade de aplicação e um alcance limitado de condições sobre as quais se aplicam. Os modelos de maior sucesso possuem alta probabilidade de aplicação e extensa gama de condições sob as quais aparecem apropriados. Com efeito, o valor de um modelo é muitas vezes diretamente relacionado ao seu nível de abstração. Capra observa que todas as "leis da natureza" 
que os modelos estabelecem são transitórias e destinadas a serem substituídas por leis mais precisas à medida que os modelos são aperfeiçoados. Esse estado provisório é atestado pelas "constantes fundamentais" (por exemplo, a velocidade da luz), ou seja, "quantidades cujos valores numéricos não são explicados pela teoria, mas que nela têm de ser inseridos após terem sido determinados empiricamente". Ainda usando os problemas de modelagem da física, verifica-se que as teorias quântica, de campos e da relatividade não podem explicar algumas grandezas que são consideradas na visão clássica constantes fundamentais da natureza. Na visão moderna, seu papel de "constantes fundamentais" é tido como algo provisório e que reflete a limitação das teorias de que dispomos ${ }^{2}$. Embora só recentemente os físicos tenham adquirido um razoável conhecimento sobre as forças nucleares, não foi ainda possível usar esse conhecimento para construir uma teoria nuclear ampla. Existe, entretanto, um grande número de modelos ou de teorias rudimentares de validade restrita, cada um deles explicando uma pequeno espectro das propriedades nucleares ${ }^{1,7}$.

Para Skilling 8 , os modelos podem ser hipóteses, hipóteses não testadas ou insuficientemente testadas, teorias, sínteses de dados, funções, relações ou equações. Podem ser, até, idéias estruturadas, conectando argumentos que apresentam algum poder explanatório. São, assim, estruturações que representam a realidade, apresentando supostas características ou relações de forma generalizada.

\section{Características dos modelos}

Herbert Stachowiak ${ }^{9}$ apresenta três características básicas dos modelos:

a) característica de mapeamento - modelos sempre modelam alguma coisa, ou seja, são representações de "originais" (ou "protótipos"), naturais ou artificiais, que, por sua vez, também podem ser modelados.

b) característica de redução - modelos geralmente não mapeam todos os atributos do original que eles representam, mas unicamente aqueles que são relevantes para quem modela.

c) característica de pragmatismo - modelos não são em si pertencentes à mesma classe que seus originais. Eles sempre cumprem suas funções de substituição orientados unicamente para objetivos dependentes de operações mentais ou factuais, dentro de uma faixa limitada de tempo.
De acordo com Hagget \& Chorley $^{5}$, a característica mais importante dos modelos é que sua construção implica uma atitude altamente seletiva em relação às informações, na qual não só as interferências como os sinais menos importantes são eliminados para permitir que se observe algo da intimidade das coisas. Desta forma, os modelos podem ser considerados como aproximações seletivas que, pela eliminação de detalhes acidentais, permitem o aparecimento de alguns aspectos fundamentais relevantes ou interessantes do mundo real sob alguma forma generalizada. A possibilidade de ser inexato e desigual em relação ao seu original é que, em última análise, permite ao modelo revelar o que se deseja.

Outra característica importante dos modelos é que eles são estruturados, no sentido de que os aspectos importantes selecionados da realidade são explorados em termos de suas relações com outros modelos e aspectos da realidade; seguem as características gerais das estruturas conforme enunciados por Piaget ${ }^{10}$, estabelecem que as estruturas constituem-se uma totalidade, com leis próprias independentes das características particulares dos seus elementos e que consistem de um sistema de operações de transformação cujo conjunto de combinações internas nunca geram produtos fora da estrutura. "A ciência tirou grande proveito desta busca de padrões, na qual os fenômenos são considerados em termos de uma espécie de relação orgânica" ${ }^{5}$; isto acontece principalmente quando se pensa em termos dos referenciais estabelecidos por Von Bertalanffy ${ }^{11}$, através da teoria geral dos sistemas, que propunha visualizar o mundo e o universo em termo de um grande conjunto interconectado, dentro do qual se poderia separar subsistemas para análise.

Esta característica dos modelos implica imediatamente a sua natureza sugestiva, no sentido de que um bom modelo traz, em si, na sua própria estrutura, sugestões para a sua própria extensão e generalização. Isto significa, primeiramente, que toda a estrutura do modelo tem maiores implicações do que um estudo de suas partes individuais e, segundo, que pelo modelo, por meio de operações e transformações proporcionadas por suas leis estruturais, podem ser feitas previsões do mundo real. Dessa forma, os modelos são instrumentos especulativos cujas implicações mais positivas conduzem a hipóteses e especulações novas no campo primário da investigação $0^{5,12,13}$. Ainda em relação à natureza estrutural dos modelos, é interessante notar que, segundo Kaplan ${ }^{14}$, o que é denominado "modelo" pelos lógicos é chamado de "estrutura" pelos economistas. 
Como bem resumem Mendonça de Souza \& Dodebei ${ }^{15}$, "por serem os modelos diferentes do mundo real, são então analogias que permitem reformular o conhecimento sobre alguns aspectos do mundo real em uma forma mais familiar, simplificada e acessível, observável e facilmente formulada ou controlável, da qual se pode tirar conclusões que, por sua vez, possam ser aplicadas no mundo real. A reaplicação é um pré-requisito dos modelos nas ciências empíricas".

\section{Funções dos modelos}

De acordo com Apostel ${ }^{4}$, "os modelos são necessários por constituírem uma ponte entre os níveis da observação e o teórico e tratam da simplificação, redução, concretização, experimentação, ação, extensão, globalização, explicação e formação da teoria". Dentro dessa perspectiva, uma das suas funções principais é a explanatória e redutora de complexidade, no sentido em que permite que uma determinada classe de fenômenos possa ser visualizada e compreendida, o que de outra forma não seria possível devido à sua magnitude e complexidade. Chorley \& Haggett ${ }^{5}$ consideram ainda a função aquisitiva, que diz respeito à estrutura proporcionada pelos modelos, através da qual a informação pode ser definida, coletada e ordenada. Além dessa função organizacional, considerase uma função que permite a otimização da extração de informações a partir do modelo - a fertilidade. Os modelos também desempenham uma função lógica que ajuda a explicar como ocorre determinado fenômeno; alinha-se também a função normativa que permite a comparação de fenômenos com outros mais familiares, além da função sistemática da construção de modelos, segundo a qual a realidade é vista em termos de sistemas interligados. Esta função conduz a uma outra, a função construtiva dos modelos que acentuam o papel destes na construção de teorias e leis. "Finalmente, há a função de parentesco dos modelos, promovendo a comunicação das idéias científicas" ${ }^{5}$. Segundo Kaplan ${ }^{14}$, esta comunicação "não é uma questão meramente de sociologia da ciência, mas intrínseca à sua lógica; como na arte, a idéia não representa nada até que tenhamos encontrado a expressão".

\section{Tipos de modelos}

Como observam Mendonça de Sousa \& Dodebei ${ }^{15}$, os modelos são tipologizados de várias formas, em função das próprias ideologias inerentes a cada autor, área de conhecimento ou ainda segundo objetivos específicos; isto significa que "considerando-se forma e expressão, os modelos podem ser agrupados ou classificados em uma série interminável de tipos". Entretanto, o termo "modelo" tem sido usado em uma variedade tão ampla de contextos que é difícil definir, sem ambigüidades, até mesmo os tipos mais gerais.

Haggett \& Chorley propõem uma classificação que pode ser interessante para os objetivos desse trabalho. Segundo esses autores, os modelos podem ser descritivos e normativos. $\mathrm{O}$ primeiro grupo trata de certa descrição estilística da realidade, e o segundo, do que se pode esperar que ocorra sob certas condições estabelecidas. Os modelos descritivos podem ser predominantemente estáticos concentrando-se nos aspectos de equilíbrio estrutural ou dinâmicos, concentrando-se, neste caso, nos processos e funções através do tempo. Quando o elemento tempo é particularmente salientado, resultam os modelos históricos ou temporais. Os modelos descritivos podem tratar da organização das informações empíricas e assim serem denominados modelos de dados, classificatórios (taxionômicos) ou de fim experimental.

Ainda segundo Haggett \& Chorley, os modelos também podem ser classificados segundo a natureza de sua constituição. Em uma primeira visão, podem ser visualizados com construções sólidas, físicas ou experimentais e, em segundo lugar, como modelos teóricos, simbólicos, conceituais ou mentais. Nos primeiros, as propriedades importantes do mundo real podem ser representadas de duas formas: modelos icônicos - as propriedades do mundo real são representadas pelas mesmas propriedades com uma mudança apenas de escala; modelos análogos - as propriedades do mundo real são representadas por propriedades diferentes. Os modelos teóricos, simbólicos, conceituais ou mentais tratam de afirmações simbólicas ou formais de tipo verbal ou matemático; os modelos matemáticos podem ainda ser classificados, segundo o grau de probabilidade associada com sua forma de previsão, em determinísticos e estocásticos.

Por fim, temos os paradigmas. "Um modelo que se revela correto e útil em uma infinidade de aplicações, em circunstâncias distintas e sobre dados diferentes, que apresenta, ao mesmo tempo, um amplo poder explanatório, pode ser definido como um paradigma”. Os paradigmas podem ser considerados como modelos estáveis da atividade científica, sendo, em certo sentido, modelos em escala ampla. Diferem, entretanto, destes no que diz respeito às suas fronteiras de validade. Os paradigmas raramente são formulados tão especificamente, trata-se de modelos de busca do mundo real. Neste sentido, os paradigmas podem ser entendidos como "supermodelos" dentro dos quais os modelos são colocados em escala mais reduzida 5 . 


\section{Modelos em sistemas de informação}

Um modelo é antes de mais nada uma representação de um recorte da realidade, que, de acordo com a sua função utilitária e por meio do seu modo de expressão, sua estrutura e suas igualdades e desigualdades em relação ao seu original, tenta comunicar algo sobre o real. Nesse sentido, um modelo de informação é uma representação de um ser humano enquanto usuário e/ou parte de um sistema de informação e das suas relações de aquisição, organização e manipulação de informação.

Burt \& Kinnucan ${ }^{6}$ referem-se à modelagem de informação como o exercício de identificação de componentes de modelos e seus elos, a explicitação dos modos de expressão, bem como o delineamento dos paradigmas e seus efeitos sobre os tipos de modelos que estão sendo construídos, pois os paradigmas refletem ao mesmo tempo os propósitos e as fronteiras de um modelo.

Em comunicação e ciência da informação, o modelo de maior sucesso e ampla utilização foi a teoria da comunicação dos matemáticos americanos Shannon \& Weaver ${ }^{29}$, que propuseram um modelo matemático para explicar a comunicação entre dois pólos, denominados "emissor" e "receptor". "Tal modelo, criticado, adaptado, modificado, ainda hoje está sendo amplamente utilizado, na medida em que, de modo preciso, simples e preditivo, propicia uma boa idéia de como se dá a comunicação humana. É, em essência, um modelo matemático, da mesma forma que as leis de Zipf, Bradford, Ortega, 80/20 e outras amplamente utilizadas na bibliometria, mas é, também, na sua concepção geral, um modelo sistêmico interligando o emissor ao receptor" ${ }^{15}$.

A ciência da informação, pela sua própria natureza ampla e interdisciplinar, para mapear toda a sua realidade, teve obrigatoriamente de tomar, como seus, paradigmas e modelos de outras áreas, tais como informática, inteligência artificial, lingüística, economia, marketing. $K u h n^{16}$ se refere às ciências cujos cientistas não são guiados por um único paradigma de "ciências preparadigmáticas"; nesse estado se encontram as ciências comportamentais, as sociais e a ciência da informação. Entretanto, Masterman ${ }^{17}$ caracteriza a ciência da informação como uma ciência multiparadigmática, dentro de uma escala em que se pode identificar as ciências "normais" e as de duplo paradigma, que são ciências normais em estado de crise, em que dois paradigmas estão em competição ${ }^{18}$.

\section{Tipos de modelos de informação}

A área de modelos e modelagem de informação caracteriza-se mais por não possuir fronteiras claras dos seus domínios internos e externos, do que por posuir um corpo coerente e consistente de trabalhos. Não obstante, esta é uma área importante e, provavelmente, sua importância será ainda maior, considerando que as pessoas e as organizações têm exigências cada vez mais sofisticadas em relação aos sistemas de informação.

Ao considerarmos todo o domínio de possibilidades dos modelos de informação, teremos, com base na proposta de Burt \& Kinnucan ${ }^{6}$, uma configuração contínua. Em um dos extremos desse contínuo está o ser humano com sua realidade pessoal, interna e presumidamente idiossincrática, ou seja, com o que chamamos conhecimento; no extremo oposto, está o sistema de informação com a sua realidade dependente dos seus próprios limites internos. Entre esses dois extremos, está localizado o campo de representações, o espaço onde se encontram representações de uma ou de outra realidade. Essas representações experimentam criar pontes ou elucidar algumas ou todas as estranhezas que se supõe existam entre essas realidades.

Os modelos que estão mais próximos do que seja a representação do usuário humano e do que se passa em sua cabeça em relação ao sistema são denominados modelos cognitivos; ao passo que os modelos que se identificam com o sistema e tentam descrever o que se passa em seu interior são mais conhecidos como modelos de dados. Na região intermediária do contínuo, é o lugar geométrico dos modelos que interpretam os usuários, o sistema e a interação entre eles; os modelos que se enquadram nesta categoria são coletivamente denominados de modelos conceituais. Dentro do escopo dos modelos cognitivos e conceituais, localiza-se um número significativo de subgrupos importantes. Não é possível, entretanto, estabelecer limites claros entre alguns desses modelos. Não obstante, Burt \& Kinnucan ${ }^{6}$ enfatizam que deve ficar clara "a distinção que se faz entre a visão individual da realidade - isto é, modelo cognitivo - e a visão que alguma outra pessoa tem de como um grupo de indivíduos devem estar vendo alguns aspectos de um sistema de Informação - isto é, modelo conceitual”.

Os autores que tentaram caracterizar esta área como um todo concordam que ela é ampla e fragmentada. Algumas regiões do contínuo, especialmente aquelas que possuem longa tradição de pesquisa, estão relativamente desenvolvidas, ao passo que outras estão praticamente 
intocadas. Vamos analisar alguns dos tipos de modelos mais importantes no contexto desse trabalho.

Modelos Cognitivos - Daniels, no seu artigo de revisão intitulado "Cognitive models in information retrieval an evaluative review" 19 , cujo propósito é sugerir como os modelos de usuário podem ser usados para otimizar o desempenho e a aceitabilidade dos sistemas de recuperação, lança um olhar crítico sobre os modelos segundo a perspectiva cognitiva e discute o seu papel na biblioteconomia e ciência da informação. Ela confirma que existe um vasto espectro de significados para os conceitos expressos por "modelo mental" ou "modelo cognitivo", mas, "de uma forma geral, modelos cognitivos podem ser considerados como imagens que os componentes de um sistema, sejam eles pessoas ou máquinas, têm de si próprios, de cada um dos outros componentes e da realidade". Isto se relaciona fortemente com o fato consensual de que, para haver comunicação entre duas partes, é necessário que cada parte tenha incorporado um modelo da outra, que muito certamente não corresponde ao modelo que cada um tem de si próprio. Allen ${ }^{20}$, nesta mesma linha, estabelece que os modelos cognitivos referemse ao conhecimento que os usuários têm sobre um sistema de informação e, em alguns casos, ao conhecimento que os sitemas de informação têm sobre os usuários.

Com o crescimento da área de pesquisa conhecida como "ciências cognitivas", interligando disciplinas tais como psicologia, lingüística, inteligência artificial, filosofia, educação e ciência da informação, o interesse pelos modelos cognitivos no âmbito da ciência da informação tem sido cada vez maior, pois os problemas de representação, informação, comunicação e conhecimento são fundamentais para todas essas disciplinas; além do mais, as pesquisas cognitivas em ciência da informação extraem os recursos metodológicos e os quadros conceituais dessas mesmas disciplinas, criando um corpo de conhecimento extraordinariamente multidisciplinar ${ }^{21,22}$. Allen ${ }^{20}$, na sua análise denominada "Cognitive research in information science: implication for design", indica-nos que o ponto de inflexão nas pesquisas cognitivas em ciência da informação foi o International Workshop on the Cognitive Viewpoint, que aconteceu em Ghent, 1977.

Desde que a matéria-prima dos processos cognitivos são "objetos mentais", tais como conceitos, idéias e conhecimento, muitos dos trabalhos nestas áreas consideram como as pessoas organizam conhecimento, como os conceitos são formados na mente humana, como as pessoas agrupam objetos em suas mentes, ou seja, como as pessoas os categorizam, quais são as teorias que as pessoas têm sobre como o mundo funciona. No contexto dos sistemas de informação, é bastante interessante para o presente trabalho os estudos de Humphrey ${ }^{23}$ sobre como os papéis assumidos por uma pessoa na sua organização influencia sua percepção e comportamento. Ele descobriu que a visão individual que cada pessoa tem sobre a sua posição na estrutura organizacional e seu fator motivacional de participação têm influência na sua avaliação e seleção da informação disponível.

Sobre a perspectiva cognitiva em biblioteconomia e ciência da informação, Daniels ${ }^{19}$ afirma que, "nos últimos anos, na área de recuperação de informação, se consolidou o consenso de que o sistema homem-computador deve ser visto como um sistema adaptativo cognitivo. A perspectiva cognitiva implica que o processamento de informação é sempre intermediado por algum tipo de modelo da realidade" e, além do mais, um sistema cognitivo pode ser considerado um sistema adaptativo cujo funcionamento, planejamento e mudanças de ações estão baseados no conhecimento de si próprio e do seu contexto.

O elenco de pesquisas que adotam a perspectiva cognitiva em recuperação da informação incluem:

a) Representação de usuários e seus problemas - modelam situações problemáticas dos usuários em face dos sistemas de informação, tais como de indivíduos cujo modelo interno de conhecimento e contextualização não é suficiente para atingimento de seus objetivos; ou ainda o "estado anômalo do conhecimento" preconizado por Belkin ${ }^{28}$, que tenta estabelecer, diante da impossibilidade de o usuário identificar o de que ele precisa, quadros (framework) através dos quais os motivos da busca de informação por parte de um usuário possam ser bem explicitados e seus resultados usados na recuperação de informação.

b) Representação de estratégias de busca - examina, por exemplo, os aspectos cognitivos do processo de transferência de informação do usuário para o especialista em informação (intermediário). A interação entre usuário e intermediários em sistemas de informação consiste, em grande parte, na construção de modelos cognitivos apropriados das várias facetas do usuário.

c) Representação de documentos e informação.

Modelos conceituais - Borgman ${ }^{24}$, que escreveu sobre a interação homem-máquina segundo uma pespectiva psicológica, sugere que os modelos mentais, no contexto de interfaces, referem-se ao modelo do usuário segundo a perspectiva do sistema, enquanto modelos conceituais são aqueles que são apresentados ao usuário pelo projetista do sistema. 
Conforme foi sugerido pelo relatório ANSI/SPARC 3,25 , um sistema de informação pode ser visualizado em três níveis: interno, conceitual e externo. $O$ nível conceitual concentra-se no "significado" (conceitos) da informação. "A tarefa de desenvolver um esquema conceitual é chamado de modelagem de informação. Seu objetivo primordial é desenvolver uma descrição estável e coerente do significado dos dados, ou seja, um esquema conceitual. Assim sendo, modelagem de informação difere da modelagem de dados, conforme desenvolvida na década de 70, que tratava principalmente da descrição de estrutura de dados (relacional, redes, hierárquicos) com vista ao acesso e armazenamento de dados", conforme analisa Lyytinen $^{26}$. Nessa linha, ele propõe duas instâncias para modelagem de informação. A primeira delas chama-se "mapeamento da realidade" (reality mapping), que é essencialmente uma técnica descritiva para representar alguma coisa que é claramente compreendida e que apresenta um comportamento sem ambigüidades. Os enfoques nos quais é baseada essa visão são relativamente comum na literatura e, basicamente, supõem um processo de mapeamento do "mundo real" em modelos formais, ou seja, em esquemas conceituais. De acordo com esta visão, "um sistema de informação é um sistema formal completamente previsível que espelha o comportamento determinístico de um universo do discurso". A necessidade de certeza em todos os níveis nesse enfoque traz uma limitação severa à sua aplicabilidade. Lyytinen prefere o segundo paradigma, "desenvolvimento de linguagem formal" (formal language development), cujo enfoque está sobre a representação, estrutura conteúdo e uso da mensagem lingüística, uma vez que ela pode lidar com maior precisão com a natureza essencialmente ambígua da maioria das configurações da realidade.

Visão do usuário/modelagem de usuário - Esses modelos apresentam interpretações de um sistema de informação real ou teórico a partir de parâmetros extraídos ou postulados de um usuário ou de um grupo de usuários que possuem características específicas que o construtor do modelo julga serem relevantes para o uso do sistema de informação. Daniels ${ }^{19}$ agrupa esses modelos em duas grandes classes: "modelos quantitativos empíricos" e "modelos cognitivos analíticos". Os primeiros são formalizações abstratas de uma classe geral de usuários definidas em termos de parâmetros de projetos de interfaces para o usuário. Tais modelos são geralmente desenhados tomando como base pessoas médias no desempenho de várias atividades em várias ambientações. Em contraste com esses modelos, os modelos cognitivos analíticos "buscam modelar aspectos do comportamento cognitivo do usuário sob o enfoque qualitativo, o que inclui: o conhecimento do usuário, seus objetivos, planos, convicções, experiência, tipo de interação preferida etc".

De uma forma geral, modelos que incorporam visões do usuário tendem a considerar diferenças entre grupos específicos de usuários ou, de uma forma mais simples, de estereótipos de usuários. Muitos desses grupos são criados, pré-concebidamente, segundo a perspectiva de desempenho ótimo dos sistemas. A dicotomia mais comum é que enquadram os usuários em "iniciantes" e "seniors", onde a habilidade modelada é a experiência no uso do computador, e não o domínio ou conhecimento da aplicação $^{6,19,26}$.

De acordo com Rich ${ }^{27,31}$, os modelos de usuários podem ser classificados segundo três dimensões principais:

a) modelo de um usuário simples, típico ou "canônico" versus uma coleção de modelos de usuários individuais;

b) modelos construídos pelo usuário ou especificados pelo projetista do sistema versus modelos pressuposto pelo computador com base no comportamento do usuário.

c) modelos de usuário de característica de longo prazo, tais como áreas de interesse e experiência versus modelos de curta validade.

Spark Jones ${ }^{19}$ sugere uma quarta dimensão, que em alguns casos pode se confundir com a terceira.

d) modelos dinâmicos, ou seja, modelos mutáveis dependendo do contexto, versus modelos estáticos, que representam as características permanentes do usuário.

Uma linha importante para os sistemas de informação diz respeito aos métodos de representação do conhecimento dos usuários e de que forma eles podem ser agrupados segundo esse pricípio. Hammond $\&$ Barnard ${ }^{19}$, por exemplo, identificaram nove tipos de conhecimento necessários a uma interação usuário versus sistema de informação. Uma segunda linha considera a maneira como alguém estrutura seus conhecimentos. Durding ${ }^{6}$, já há algum tempo, demonstrou que as pessoas usam estruturas distintas, tais como redes e estruturas hierárquicas, para organizar conceitos quando estas estruturas são próprias e inerentes aos itens que estão sendo processados. Diagramas e outros tipos de representação gráfica também são úteis na estruturação de conhecimento. Os usuários de bases de dados organizadas hierarquicamente fazem buscas mais eficientemente quando estão de posse de um "mapa" com 
a estrutura de árvore da base de dados. Provavelmente o diagrama possibilita ao usuário chance de conceber a sua própria representação hierárquica da base de dados $6,19,20$.

Modelos Semânticos de Dados - Modelos de dados representam a área mais próxima do sistema e de sua realidade interna. $\mathrm{O}$ modelo hierárquico, o modelo de redes, bem como o modelo relacional de $\operatorname{Codd}^{30}$, são tradicionais representantes de modelos de dados; tipicamente essa categoria de modelos enfatiza os aspectos sintáticos e estruturais dos dados sem, entretanto, considerar o significado dos dados ou o relacionamento próprio e lógico entre eles. Com o advento de sistemas de informações mais sofisticados e de maior abrangência, tornou-se absolutamente necessário o desenvolvimento de modelos que viessem facilitar o entendimento do usuário em relação ao sistema e ao mesmo tempo evitassem o envolvimento dele com a estrutura física dos dados dentro do computador. As pesquisas nessa área se concentram predominantemente no desenvolvimento de modelos que espelhem com maior fidelidade a "complexidade semântica do mundo real da informação". Com efeito, nos últimos anos, os pesquisadores da área de banco de dados voltam suas inteligências no sentido de incorporar aspectos comportamentais (ou dinâmicos) de dados nos formalismos de modelagem; este trabalho tem sido fortemente influenciado pelo paradigma da programação orientada por objetos. Modelos que caminham nesta direção são denominados pela literatura de "modelos semânticos de dados"32,33.

Tsicchritzis \& Lochovsky ${ }^{34}$ consideram que o papel próprio dos modelos de dados é servir como um meio de comunicação dirigido às pessoas em geral, de forma que a estrutura imposta pelo modelo não poderia discordar da estrutura natural da realidade tal como ela é percebida pelo usuário humano. Dentro dessa perspectiva, eles discutem a proposta de dois tipos de modelos de dados: o primeiro deles lidaria com o mapeamento das informações do mundo real em conceitos básicos humanos - domínio infológico (infological realm); em uma segunda instância teríamos o domínio datalógico (datalogical realm), que mapearia estes conceitos básicos humanos em representações em computador. Neste caso, os modelos de dados tradicionais estariam categorizados como "datalógicos", ao passo que os modelos de dados semânticos seriam, ao menos, o primeiro passo em direção aos modelos "infológicos".

Os modelos conceituais de dados conhecidos foram criados como ferramentas de representação que funcionam em ambientes específicos, e, assim sendo, a literatura não reconhece nenhum modelo generalizado. Hull \& King ${ }^{32}$ concluem que, apesar da dificuldade de definições precisas, a literatura aponta uma trajetória evolucionária para a área de modelos semânticos de dados. As pesquisas nesta área estão relacionadas principalmente na extensão do modelo relacional, de forma a enriquecê-lo com abstrações semânticas provenientes da pesquisa em lingüística.

As abstrações semânticas são formas de especificar relacionamentos entre conceitos lingüísticos que trabalham as diferenças sutis de significado. Burt \& Kinnucan ${ }^{6}$ enunciam quatro dessas abstrações como as mais comumentes usadas nos modelos semânticos: generalização, agregação, classificação e associação.

a) Generalização - Esta abstração ocorre quando objetos ou entidades são agrupados em um relacionamento hierárquico no qual os objetos do nível mais baixo são vistos como subtipos daqueles de nível mais alto. Por exemplo, os objetos "biografias" e "novelas" podem ser visualizados como exemplares específicos do objeto "livro". Este tipo de agregação é conhecido como uma relação "ÉUM" (em inglês: "IS-A" ou "ISA") ${ }^{32}$.

b) Agregação - Esta abstração ocorre quando objetos são agrupados em um relacionamento de composição, onde cada objeto contribui para a formação de visualizações específicas de um objeto maior. Por exemplo: os objetos "página", "capa", "encadernação" e "tinta" podem ser agrupados para formar uma visão do objeto "livro"; enquanto o "título", "autor" e "editor" podem ser agrupados para formar uma outra visão. Este relacionamento é também conhecido como relacionamento "É-PARTE-DE" (em inglês: "IS-PARTOF").

c) Classificação - Esta abstração ocorre quando objetos são agrupados por serem exemplos particulares de um tipo mais geral. Por exemplo: "Sagarana" e "O estorvo" são exemplos de "novelas". Este relacionamento é também conhecido como relacionamento "É-EXEMPLO-DE" (em inglês: "IS-INSTANCE-OF").

d) Associação - Esta abstração ocorre quando objetos são agrupados segundo a sua virtude em satisfazer algum critério. Este relacionamento é também conhecido como relacionamento "É-MEMBRO-DE" (em inglês: "ISMEMBER-OF”).

Hull \& King ${ }^{32}$ fazem, ainda, uma distinção entre modelos semânticos que "incorporam aspectos estruturais dos objetos" e modelos orientados a objeto que "incorporam aspectos comportamentais dos objetos". O enfoque da 
orientação a objeto "simplesmente desloca a ênfase do relacionamento entre os componentes do modelo para o comportamento dos componentes individuais ou componentes grupais, onde quanto mais graus de liberdade estão presente no comportamento do objeto mais fortemente ele será caracterizado".

Conforme visto, os modelos que mais e mais desempenham um papel importante como recurso metodológico para todas as áreas cujo interesse são os fenômenos relacionados à informação, como informática e ciência da informação. Acerca do papel das ferramentas de modelagem para o desenvolvimento das atividades profissionais do cientistas da informação, Burt \& Kinnucan ${ }^{6}$ afirmam que "os cientistas da informação (...) podem encontrar, nas técnicas de modelagem, um mecanismo útil para capturar e comunicar seus conhecimentos sobre fontes de informação e sobre padrões de comportamento de quem busca informação. Os modelos resultantes podem ser amplamente desenvolvidos mediante seleção e composição de conceitos e técnicas de modelagem provenientes de várias disciplinas (informática, psicologia, física, lingüística e outras).

Por fim, mais pesquisas sobre como as pessoas usam, selecionam e se posicionam diante da informação são extremamente necessárias para a concepção e projetos de sistemas de informação que preencham com mais completeza as necessidades dos usuários desses sistemas.

\section{REFERÊNCIAS BIBLIOGRÁFICAS}

1. ALMEIDA, Elizabeth; TAUHATA, Luiz. Física nuclear. Rio de Janeiro: Guanabara Dois, 1981. 413p.

2. CAPRA, Fritjof. O tao da física. São Paulo : Cultrix, 1983. 160p.

3. SETZER, Waldemar. Projeto lógico e projeto físico de base de dados. Belo Horizonte : UFMG, 1986. 284p.

4. APOSTEL, L. Toward the formal study of models in the non-formal sciences. In: FREUDENTHAL, H. The concept and the role of the model in mathematics and natural and socials sciences. Amsterdam : Dordtreccht, 1991. p.1-37.

5. CHORLEY, Richard; Haggett, Peter. Modelos, paradigmas e a nova geografia. In: CHORLEY, Richard, HAGGETT, Peter. Modelos sócioseconômicos em geografia. Rio de janeiro : Livros Técnicos e Científicos/ USP, 1975. p.1-22.

6. BURT, Patricia; KINNUCAN, Mark. Information models and modelling techniques for information systems. Annual Review of Information Science and Technology, p.175-208, 1990.

7. EISBERG, Robert; RESNICK, Robert. Quantum physics of atoms, molecules, solids, nuclei, and particles. New York : John Wiley, 1974. 713p.

8. SKILliNG, H. An operational view. American Scientist. v.52, p. 388 396, 1964.

9. STACHOWIAC, Herbert. Models. In: SCIENTIFIC thought: concepts, methods and procedures. Paris : Unesco, 1972, p. 145-166.

10. PIAGET, Jean. The concept of structure. In: SCIENTIFIC thought: concepts, methods and procedures. Paris : Unesco, 1972. p.35-56.

11. BERTALANFFY, Ludwig. General system theory: a critical review. General Systems, v.7, p.1- 20, 1962.

12. BLACK, M. Models and methaphors. New York: Ithaca, 1962. 267 p.

13. HESSE, M. Models in physics. British Journal of the Philosophy of Science. v. 4, p. 198-214, 1953-1954.

14. KAPLAN, A. The conduct of inquiry. San Francisco : Chandler, 1964. $428 \mathrm{p}$.

15. SOUZA, MENDONÇA A. DE; DODEBEI, V. L. Modelos e sistemas em ciência da informação. Rio de Janeiro, 1993. 20 p. (Seminário apresentado à disciplina Linguagem e Ciência da Informação III. Curso de Doutorado em Ciência da Informação).

16. KUHN, T.S. The structure of scientific revolutions. Chicago : University of Chicago, 1970.

17. MASTERMAN, M. The nature of a paradigm. In: LAKATOS, I.,MUSGRAVE, A. Criticsim and the growth of knowledge. Cambridge : Cambridge University, 1970. p. 59-91.

18. ELLIS, David. The physical and cognitive paradigms in information retrieval research. Journal of Documentation, v. 48, n. 1, p. 389-392, Mar. 1992.

19. DANIELS, P.J. Cognitive models in information retrieval: an evaluative review. Journal of Documentation, v. 42, n. 4, p. 272-304, Dec. 1986.

20. ALLEN, Bryce L. Cognitive research in information science. Annual Review of Information Science and Technology, v. 26, p. 3-37, 1991.

21. GAINES, Brian R. Modeling and forecasting the information sciences. Information Sciences, v. 57-58, p. 3-22, 1991.

22. VICKERY, B. C. Knowledge representation: a brief review. Journal of Documentation, v. 42, n. 3, p. 145-159, Sep. 1986.

23. HUMPHREY, Ronald. How work roles influence perception: structural cognitive processes and organizational behavior. American Sociological Review, v. 50, n. 2, p. 242-252, 1985. 


\section{Modelos teóricos em ciência da informação - abstração e método científico}

24. BORGMAN, Christine L. The user's mental model of an information retrieval system: an experiment on a prototype online catalog. International Journal of man-machine studies. v. 24, p. 47-64, 1986.

25. ANSI/X3/SPARC. Study group on data base management system. FDT-Bulletin, v. 7, n. 2, 1975.

26. LYYTINEN, Kalle. Two views of information modelling. Information $\mathcal{E}$ Management, v. 12, p. 9-19, 1987

27. RICH, Elaine. User modelling via esterotypes. Cognitive Sciences, v. 3, p. 329-352, 1979.

28. BELKIN, Nicholas J. Anomalous states of knowledges as a basis for information retrieval. Canadian Journal of Information Science, v. 5, p. 133. 140, 1980.

29. SHANNON, Claude; WEAVER, Warren. The mathematical theory of communication. Urbana : University of Illinois Press, 1949.

30. CODD, E. F. Extending the relational model to capture more meaning. ACM Transactions on Database Systems, v. 4, n. 4, p. 397-434, Dec. 1979.

31. RICH, Elaine. Users are individuals : individualizing user models. International Journal of Man-Machine Studies, v. 18, n. 3, p. 199-214, Mar. 1983.

32. HULL, Richard; KING, Roger. Semantic database modelling: survey, aplications, and research issues. ACM Computing Surveys, v. 19, n. 3, p. 201-260, Sep. 1987.
33. CHEN, Peter P. The entity-relational model - toward a unified view of data. ACM Transactions on Database Systems, v. 1, n. 1, p. 9-36, Mar. 1976.

34. TSICHRITZIS, D., LOCHOVSKY, F.H. Data models. New Jersey : Prentice-Hall, 1982. 381 p.

35. BELKIN, Nicholas J., ROBERTSON, Sthephen E. Information Science and the phenomenon of information. Journal of the American Society for Information Science, p. 197-204, Jul./Aug. 1976.

36. FARRADANE, J. The nature of information. Journal of Information Science, v. 1, n. 1, p. 13-17, 1979.

37. SMITH, Linda C.; WARNER, Amy J. A taxonomy of representations in information retrieval system design. Journal of Information Science, v. 8, p. 113-121, 1984.

38. GILBERT, Nigel G. Cognitive and social models of the user. In: INTERACT: HUMAN-COMPUTER INTERACTION, 87., 1987, Amsterdan. Proceeding of the Second IFIP Conference. North-Holland : Elsevier, 1987. p.165-169.

39. WIESER, Wolfgang. Organismos, estruturas, máquinas: para uma estrutura do organismo. São Paulo : Cultrix, 1972, 124 p. 